Please share your stories about how Open Access to this article benefits you.

\title{
Swing: From Time to Torque \\ (Dance Floor Democracy at the \\ Hollywood Canteen)
}

by Sherrie Tucker

2013

This is the published version of the article, made available with the permission of the publisher. The original published version can be found at the link below.

Sherrie Tucker. (2013). "Swing: From Time to Torque (Dance Floor Democracy at the Hollywood Canteen." Daedalus: Journal of the American Academy of Arts \& Sciences 142(4):82-97.

Published version: http://www.dx.doi.org/10.1162/DAED_a_o0243

Terms of Use: http://www2.ku.edu/ scholar/docs/license.shtml 


\title{
Swing: From Time to Torque (Dance Floor Democracy at the Hollywood Canteen)
}

\author{
Sherrie Tucker
}

\begin{abstract}
The Hollywood Canteen (1942-1945) was the most famous of the USO and USO-like patriotic nightclubs where civilian hostesses jitterbugged with enlisted men of the Allied Nations during World War II. It is also the subject of much U.S. national nostalgia about the "Good War" and "Greatest Generation." Drawing from oral histories with civilian volunteers and military guests who danced at the Hollywood Canteen, this article focuses on the ways that interviewees navigated the forceful narrative terrain of national nostalgia, sometimes supporting it, sometimes pulling away from or pushing it in critical ways, and usually a little of each. This article posits a new interpretative method for analyzing struggles over "democracy" for jazz and swing studies through a focus on "torque" that brings together oral history, improvisation studies, and dance studies to bear on engaging interviewees' embodied narratives on ideologically loaded ground, improvising on the past in the present.
\end{abstract}

SHERRIE TUCKER is Professor of American Studies at the University of Kansas, Lawrence. She is the author of Swing Shift: "All-Girl" Bands of the 1940s (2000) and coeditor of Big Ears: Listening for Gender in Jazz Studies (with Nichole T. Rustin, 2008). Her articles have appeared in such journals as American Music, Black Music Research Journal, and Critical Studies in Improvisation.
There is No Color Line at This Coast Canteen

- Chicago Defender, January 30, 1943

What does it mean to have a body that provides an institution with diversity?

- Sara Ahmed, On Being Included ${ }^{1}$

Democracy! That's what it means, Slim! Everybody equal. Like tonight! All them big shots, listening to little shots like me, and being friendly!

- Sgt. Brooklyn Nolan, Hollywood Canteen (1944)

$\mathrm{T}_{\mathrm{h}}$ Hollywood Canteen (October 3, $1942-$ November 22, 1945) was the most famous of the thousands of USO-like nightclubs where civilians entertained military personnel during World War II. Patterned after New York's Stage Door Canteen, the club featured volunteers who hailed mostly from the guild and unions of the motion picture industry, including glamorous stars like Rita Hayworth, Deanna Durbin, and Hedy LaMarr. Bette Davis was the president of the Hollywood Can-

(C) 2013 by Sherrie Tucker

doi:10.1162/DAED_a_00243 
teen; John Garfield was vice president. In its own time, the Hollywood Canteen became a powerful backdrop for publicity photos of movie stars appearing patriotic by jitterbugging to swing music with soldiers, feeding them, signing autographs, and generally being friendly and generous with their time, beauty, and fame. The Canteen remains one of the most recognizable articulations of swing as a symbol of the United States, its jitterbugging soldiers and glamorous hostesses epitomizing a selfless, innocent "Greatest Generation," a unified nation of "Good War" nostalgia.

Yet the Hollywood Canteen is also remembered as the site of conflict when Canteen board members fought over whether people could dance across race lines. When challenged by those less keen on integration, Bette Davis and John Garfield, along with members of the segregated locals of the Los Angeles musicians unions, threatened to pull their support. While the "knockdown drag out fights" about integrated dancing (in segregated Hollywood) might suggest that all was not well at the dance floor of the nation, the narratives that circulated about these battles served to prove that the Hollywood Canteen was an especially democratic space. Such civil rights angles dominated Canteen coverage in the national black press, popular front press, and Down Beat, while mentions of racemixing at the Canteen were absent from the mainstream press. $^{2}$ The democratic, integrated dance floor became prominent in biographies and autobiographies of celebrities of the era, and is well covered in scholarship by historians of jazz and swing, World War II, and Los Angeles, as well as in World War II documentaries and museum plaques. ${ }^{3}$ Nonetheless, the lasting image in national memory is the white jitterbugging starlet and soldier.
This article is part of a larger study in Sherrie which I take the dance floor of the Holly- Tucker wood Canteen as a lens for exploring swing culture as war memory in the United States. By war memory, I am thinking of the cultural repository that literature scholar Marianna Torgovnick has called the war complex, or the particular ways that national memory of World War II continues to express, for many Americans, "how we like to think of ourselves and to present ourselves to the world, even at those times when the United States has been a belligerent and notmuch-loved nation." 4 The Hollywood Canteen is part of a larger package of nostalgia of uncomplicated American goodness during World War II that has played, and continues to play, a powerful role in constructing national memory and recruiting patriotic identification (even for those too young to remember the war). What explains the persistent appeal of swing dance, and what alternate narratives are forgotten when swing memory as war memory is the only one remembered? Of the sixty people I interviewed, most of the white participants remembered an integrated dance floor, while most people of color remember a segregated, or partially segregated, space. Nearly everyone thought the Canteen had something to tell us about democracy in the United States. It is in the push and pull of those multiple, contradictory, differently embodied orientations to Hollywood Canteen memory that I've found a new way to dance as a swing scholar interested in music, race, and democracy.

This essay focuses, in part, on Amiri Baraka's (then LeRoi Jones) grammatical intervention indicated in the title of his Blues People essay "Swing: From Verb to Noun." 5 In this piece, Baraka identifies effects of cross-cultural musical travels from black to white America by tracking the historical route of swing from some- 
Swing: thing African American musicians did with From Time pulse and forward motion in big band
to Torque music in the late 1920 s through the 1930s, to the static commodity that became known as Swing, a brand name genre that after 1935 spoke primarily to mainstream white America (and middle-class black America), and that largely withheld profits and jobs from African American musicians. In the war years, swing was not only a brand, but a kind of national anthem for the United States, then fighting for world democracy with segregated armed forces, segregated blood supplies, and a social, legal, material, and spatial landscape entrenched in uneven and inconsistent rules about race that white people often were oblivious to. The Hollywood Canteen, with its iconic jitterbugging hostess and soldier, functioning as war memory about a Greatest Generation conceived as diverse, but nearly always depicted as white, would seem to epitomize the noun-side of Baraka's analysis.

But my adherence to Baraka's verb/noun analysis was challenged by conversations with diverse former Canteen-goers, who told wildly different stories about their bodies on the late swing era dance floor. Poet and novelist Nate Mackey's 1995 twist on Baraka's essay, "Other: From Noun to Verb," helps our understanding with an alternative grammatical intervention, moving the concept of other, rather than swing, from noun to verb form. ${ }^{6}$ Mackey intended to shake up institutional multiculturalism "redress" projects that "nounify" aggrieved communities as "others" for the institution to assist, manage, and include. A multiculturalism project that seeks to diversify white space by including others resembles what race scholar Sara Ahmed has called the hospitality model of diversity, in which "whiteness is produced as host, as that which is already in place or at home. To be welcomed is to be positioned as the one who is not at home."7 Mackey argues for a practice that would remember that other is what people do ; it is not what people are. Drawing a distinction between two verb forms of other, he identifies 1) artistic othering as a practice of "innovation, invention, change on which cultural health and diversity depend and thrive"; and 2) social othering as "the centralizing of a norm against which otherness is measured, meted out, marginalized." 8 The cultural verb "to swing," then, is but one of many examples of artistic othering practices of African Americans, people who have been subjected to social othering. Guests and volunteers at the Hollywood Canteen did and experienced both.

Social dancing and its music are both social and artistic practices - and dancers who swing to music that swings may navigate social othering and artistic othering in dynamic tension, even in the most noun-destined times and places. Writing about another dance floor in her book I Want to Be Ready: Improvised Dance as a Practice of Freedom, dance and movement scholar Danielle Goldman argues that although New York's Palladium was unique in its integration in the 1950s, it was still "not a 'free' space where everything was equal and anything was possible." But rather than taking evidence of contradiction as occasion to debunk the integrated dance hall, Goldman emphasizes the importance of attending to multidirectional desires and interpretations. In her analysis of improvised dance as a "practice of freedom," she acknowledges that a "variety of constraints imposed by racism, sexism, and physical training shaped how people moved," and that one dancer's experience of a powerful moment, "while meaningful in many ways, [was] neither shared by, nor identical for the dance hall's many patrons."9 For Goldman, to let go of an assumption of "sameness" or consensus of dance expe- 
rience does not diminish the political power of dancers' abilities to "interact with constraints," and in fact, it comprises "the possibility for meaningful exchange." 10 The contradictions and incompatibilities of dance floor memories at the Hollywood Canteen are absolutely necessary to understand its democratic potential.

An assumption of sameness dominates the either/or noun-verb dichotomy in scholarship on swing's ability to represent American identity. For African American studies scholar Perry Hall, the polarized analyses are that: 1) swing was an unusually integrated cultural formation, expressing populism and multiethnic, multicultural, and interracial mixing as particularly American; or 2) swing represented a blatant example of white American appropriation of black American culture. ${ }^{11}$

Rather than arguing one side or the other, I am interested in swing's capacity to slip between these poles. If, as cultural and gender theorist Inderpal Grewal has argued, America continues to be imagined as simultaneously multicultural and white, both within the United States and from the perspective of other nations, ${ }^{12}$ then the easy slide between swing as either multicultural populism or white domination defines its symbolic potency. How neatly the popular national narratives about swing musicians who pioneered the integration of a segregated industry, and patriotic jitterbug dancers who integrated the dance floor, fit what historian Nikhil Pal Singh has called "civic myths about the triumph over racial injustice" that have become "central to the resuscitation of a vigorous and strident form of American exceptionalism."13

When swing culture is narrated as America's "triumph over racial injustice," it drowns out critical opportunities for examining continuing inequalities. Per- haps it is precisely swing's dual history as Sherrie musical melting pot and crime scene of Tucker appropriation that positions it to acquire such a seductive national memory as universally American and democratic. What if swing excels as a national music, not in spite of, but because of its ability to mean different things to many people, while also signaling a unified wartime America? Although the image of the idealized soldier-hostess jitterbugging couple was presented at the time (and rolled out many times since) as a nostalgic representation of national unity and American likability in a time of war, the former Canteen-goers that I talked to often narrated the hinges of noun and verb forms of swing and other. Listening to former Canteen-goers remembering their young swing-dancing bodies is one way to remember connections between the dance floor and the commotion against its surface, to explore in swing memory the tensions of America as the many and the one.

When swing scholarship shifts from music to dance, the analytic center tends to pivot from time to torque. "To swing," defined by jazz and swing scholars who focus primarily on music, tends to apply to conjugation of rhythm, tempo, pulse, and the forward motion often, but not always, achieved in the emphasized second and fourth beats of the four-four rhythm. Jazz critic Kevin Whitehead describes swing as a "headlong, but relaxed sense of propulsion, as if the music was skipping down the sidewalk. It often relies on small surges and hesitations, on placing a note or accent just in front of or behind where a metronome or tapping foot would put it." But, he adds, "Count Basie's bassist Walter Page could place his notes squarely on the beat and swing like crazy."14

When dance scholars talk about swing, however, we enter a world of physics, the 
Swing: "centrifugal force, torque, and momenFrom Time tum" that "keep the partners spinning to Torque smoothly."15 Historian Lewis Erenberg has emphasized the role of the "intimate communication" of the "dance's hand clasp," necessary in order to ensure "that the couple could survive the centrifugal force and the obstacles of the dance." 16 Jazz historian Howard Spring has argued that it was this new "more physical" way of dancing - involving more parts of the body and more movements per measure (four instead of two)-that spurred the new musical approaches to rhythm and timbre in the music that became known as swing. ${ }^{17}$ Swing dance scholars often identify the radical reworking of "ballroom conventions of leaders and followers" into what historian Terry Monaghan called a more "mutually assertive" relationship. ${ }^{18}$

Many scholars have highlighted the "breakaway" as the defining property of the lindy hop and jitterbug, representing the integration of individual and community, improvised solo and ensemble - the dance version of what has been celebrated as the democratic principle of jazz. "In most couple dances (the waltz and the foxtrot, for instance)," writes philosopher Robert Crease in his exploration of Hollywood representations of the lindy hop, "the partners hold each other closely enough so that they generally need to do identical footwork with reverse parity lest they tread on each other's feet." What was radically new in the lindy, then, was the "development of the breakaway," which "made possible a flexible couple dance with room for improvisation. Partners could do markedly different steps - even ones unknown to and unanticipated by one's partner as long as the basic rhythm was preserved."19 It was the "continuous rhythmic play" and "driving reciprocal dynamic" of dance partners that Monaghan identified as swing's "aesthetic articulation of cultural equity."

To onlookers, the lindy or jitterbug may look like a back-and-forth, in-andout motion. But to dancers, "swing" is less like the sway of a pendulum, and more like what would happen if you could "swing" that pendulum at the end of a string around and around over your head. ${ }^{20}$ The heavy end becomes airborne and seems almost weightless only when you achieve the optimum combination of force, rotation, and distance. Swing it too placidly and it doesn't get off the ground. Swing it too hard and the string slips out of your hand and the pendulum flies through the neighbor's window. But swing it just right, just fast enough, with just enough bend to the arm to adjust the speed for the weight - torque it accurately and you and your dance partner achieve a greater level of turning power than either could achieve alone.

In their book Physics and the Art of Dance: Understanding Movement, physicist Kenneth Laws and dance pedagogue Arleen Sugano define torque as "a kind of force that causes a rotation, like the hand turning a screwdriver or two hands turning a T-shaped wrench to tighten bolts on a car wheel." 21 For solo dancers, torque is applied to the floor through the feet, one pushing one way and one the other. In partner dance, the floor and feet still do this work, but in relation to the torque dancers apply to one another. Like a physicist, the experienced swing dancer appears to defy gravity, not by fighting it, but by knowing its rules, and using this knowledge to accurately apply the laws of turning power, weight, velocity, distance, and shape. The swing, then, for the lindy or jitterbug, is not all in the rhythm, the tempo, or even the steps. Swing is in the crouch, bend, lean, weight, speed, balance-torque. Music that swings, for experienced swing danc- 
ers, is music conducive to the achievement of torque.

Writer and performer Brenda Dixon Gottschild has observed that although the dance was "gender-democratic" in the relatively shared athleticism of the lead and follow, race democracy was limited when white rebellion was projected onto black survival. She argues that the lindy hop was titillating to white youth "in flight from the Protestant ethic" in ways it could not be to African American youth living "on the edge, literally and figuratively." 22 The same pivot points that contributed to the lindy's "potential to undermine and subvert racism" and that led to integration of racially segregated space ("almost always in the black community") also rendered swing culture ripe for white primitivist titillation. For white dancers socialized in a culture that constructed blackness as undisciplined, ecstatic, and prone to sexual abandon, the swing-out was about letting go of all control, missing altogether what was new in the lindy for black dancers. ${ }^{23}$ By the 1940s, the shift from the lindy to the jitterbug (amid other changes accompanying the mainstreaming of swing) sometimes obscured its origins in black culture. But even this cross-cultural amnesia could not prevent the flow of "primitivist" associations for many white social dancers (and film directors) who often saw the jitterbug as pulling out the stops, rather than as a communicative partnership between a (more) democratized lead and follow that sought flight through balance.

Among other things, the Hollywood Canteen was a democratically conceived, explicitly patriotic, mostly white, supposedly integrated dance floor in a segregated white part of Los Angeles (a sprawling city, most of which was, in the 1940 s, permeated with racially restrictive housing covenants). What desires ani- mated the dance of people blocked by Sherrie restaurant and nightclub admission poli- Tucker cies, as well as the people who were largely unaware that Los Angeles was segregated? Many different cultural associations, embodied experiences, and skill levels were brought to dance. An exuberant lead who learned from the movies might fling his protesting partner around like a rag doll, while a flight-ready follow may never snap her partner out of his selfconscious two-step (one interviewee called it "the GI shuffle"). But it was also possible to achieve mutually enjoyable (though differently experienced) torque: to connect with another through touch and feel, find the point of connection in which bodies move one another, improvising across shared or different orientations (including degrees of resistance, centers of gravity, and mass) and strike a balanced pattern of tension and release that maintained "I" and "we," the individual and the collective - what we might call the physics of swing democracy. The breakaway didn't facilitate this on its own. Neither did the couple steps. The swing is in the torque, without which the breakaway and coupling have no connection. At the Hollywood Canteen, and elsewhere, dance floor democracy is collaborative and physical and not guaranteed.

How might we reconceptualize the articulation of democracy and swing culture as the torque as practiced on the unsteady dance floor, and not in the reassuring rocking motion of the pendulum swing or in the patterned opportunities for relative freedom and individualism in the breakaway? How do we speak of torque in relation to social power imbalances of race, gender, class, sex, and rank? Is there a way to store past torque for the future, in self-narrative, for example, in stories of improvised moves on the dance floor? Nostalgia is emptied of torque. But some ways of remembering 
Swing: and telling turn the nostalgia into someFrom Time thing else, through tone and gesture,
to Torque to Torque humor, and critique. How do people apply turning power to narrative performances of memory? Sometimes, the torque is in the telling.

$\mathrm{O}_{n}$ ne dancer narrates her body dancing in an unexpected way: perhaps she breaks the rules, dances across race. Somehow this breach creates an even more democratic dance floor narrative than if there hadn't been a rule to break. Another would-be dancer describes the impact of rejection on the "inclusive" dance floor, maps what it should have been like as a vision of democracy. Another compares the Hollywood Canteen with another, even more democratic dance floor in a more racially inclusive neighborhood of Los Angeles. Another ascribes the democratic achievement of the Hollywood Canteen to the radicals on the staff, rather than to the inherent niceness of Tom Brokaw's Greatest Generation.

Literary scholar and oral historian Alessandro Portelli argues that the point of oral history is not to replace "previous truths with alternative ones," but to listen to them together, for how "each provides the standard against which the other is recognized and defined." 24 Listening to the oral narratives in relation to one another, to the official story, and to archival documents, I am not sifting evidence for a preferable version of the past. Instead, I listen for relationships - pulling together and pushing apart - to better understand the persistence and performativity of swing culture as war memory.

I hear the "official" memory of the Hollywood Canteen in virtually every interview; sometimes in unison with it, sometimes in dissonance, and usually a little of each. Oftentimes, there is some point at which I hear the familiar tune torqued in the telling, in which the teller leans away from the official memory, applying a bit of pressure that changes its direction or meaning. From my own dance as an interviewer, researcher, scholar, and writer, I try to pick up new kinds of critical engagements with swing culture as war memory. Instead of reifying or debunking the nostalgia, I listen for what happens to the nostalgia in Canteengoers' narratives as they tell me about the club, as well as the social, geographical, and historical ground navigated on their way to, through, and out of it, and how they connect that with the present moment of the interview. I ask for the dance - then try to follow - though I am, of course, the one who initiates, records, and analyzes the event. I ask questions. They answer. But they also ask questions and I answer. I try to lead in such a way that I eventually follow, I want to follow - at least until I return to my office, where I will write about the event without my partners' input. But in the moment of the dance, my listening/following body sends intended and unintended responses to my partners, who read me, perhaps changing directions as a result of something that happens between us a laugh, a missed joke, body language read as interest or disinterest - as my partners narrate order into the disorder I initiated when I ask them to share memories of their visits to the Hollywood Canteen.

I careened out of each interview rethinking the jitterbugging soldier-hostess dyad, not as a closed symbol of the nation, but an opening for thinking from more than one side, and even more than two sides. For dancers, the dyad was serial and temporary, moving from one partner to another in gendered roles of "lead" and "follow." I did not literally dance with my interviewees, but I did interact with them in their homes, apartments, retirement facilities, and over the phone, seeking connection on the narrative ground of dance. We tested each other's 
responses and moved accordingly; interpreting each other in the moment, trading questions and answers, follow-up questions and stories. I felt myself pulled into many relationships and orientations to swing's national potency in the 1940 s and the present, meanings that never stray too far from the race of space and bodies, be it multicultural bodies in colorblind space, blatant segregation, or the defeat of the color line. My interviews with former Canteen dancers often felt like what sociologist Black Hawk Hancock has called embodied practices of race. $^{25}$

“A

Are you black or white?" asked Mel Bryant, within the first five minutes of our first telephone conversation about the Hollywood Canteen.

So far, I had been leading. I initiated the call (referred by his sister, trumpet player Clora Bryant, whom I had interviewed many times for my book on all-woman bands). I introduced myself, and told him that his sister had mentioned that he had attended the Hollywood Canteen while on leave from the Marines. He said yes, this was true. I asked him if I could interview him for my book (yes, again). Then I asked him if the dance floor was integrated, as reported in the black press, the musicians' union magazine, and Down Beat.

"Don't you believe it, Sherrie," he replied. "Don't you believe it."

I hadn't believed that a dance floor in Hollywood at that time could be easily integrated, and I was eager to learn more about how the Hollywood Canteen fell short of its stated goals. I knew that Mel had been a Los Angeles-based actor for most of his life, and that he would have a unique perspective as an African American military guest who would have already known the limits of segregated Hollywood within the social geography of Los Angeles, in which most people of Sherrie color lived south of downtown and east Tucker of Main in what was, in the 1940s, known as the Eastside, but is today known as South L.A. Feeling we were on the same page, I asked my usual follow-up questions: "What happened? What were the rules?"

This is where Mel took the lead.

"Are you black or white?" he asked.

"I'm white," I said.

Somehow, I got the sense that this didn't surprise him. But my racial identification, once said aloud, became a mutually conscious part of our interaction. Our interview turned in different ways than if I had been able to continue to abstractly sense myself as racially neutral (a white habit, and a researcher habit, intensified by the telephone). Now, as Mel gave me an answer, it was in the context of what had become an overtly cross-racial dance.

“For black people, integration isn't just about rules. It's about body language and a look on the face. There doesn't have to be a rope across the room. No one has to say anything for you to know when you are not wanted." 26

I am not the first white person Mel had explained this to in his lifetime. Asking me to racially identify had a performative function in our conversation, shifting the concept of racial integration out of the realm of policy or intentions and into the realm of embodied knowledge. My questions about "what happened" and "what were the rules" did not get at his embodied experiences, memories, or what he had to say about the dance floor at the Hollywood Canteen. Race at this point in the interview has to do with different orientations to the question of what constitutes an integrated social space. What Mel had to say about his memories of the dance floor did not fit the framework I presented, in which a club was either integrated or segregated, where we could name 
Swing: what was happening and pin down the From Time rules.

to Torque In asking me to racially identify, Mel reoriented our conversation so that it had room for his embodied knowledge, shaped by a Jim Crow childhood growing up in a small segregated Texas town, a career as an actor spent moving through predominantly white crowds in a racially marked body, basic training with other black recruits under white officers at Montford Point, a furlough spent trying to reconnect with his new hometown and interrupted acting career in Los Angeles, and memories of his long postwar acting career. To white Canteen-goers, the presence of a lone black body moving through an otherwise apparently white crowd could be seen as evidence of integration (interpreted as either a symbol of America or a caution of un-Americanism in Hollywood, depending on the viewers' visions of how racial difference and democracy were interconnected - both interpretations had currency during World War II). But from the perspective of the person or persons whose burden it is to integrate the room, this same event could register as evidence of white space, a lack of integration.

Mel is explaining to me, explicitly as one black person explaining something to one white person, how, from the perspective of a black person, the text of the crowd - the "body language" and "look on the face" - could indicate a segregated space, even if a black Marine was welcomed into the club. This kind of segregation could pass as integration to most white people in a Hollywood night spot. "The Hollywood Canteen is something to be remembered, and something to be regretted," said Mel. "It was a different thing, a wonderful thing to have a place where soldiers could go, but it wasn't integrated in an equal way." 27

I emerged from this first of two telephone interviews with Mel Bryant, turn- ing in a new direction. Instead of standing with Mel, facing an imperfectly integrated Canteen, I had turned toward him and listened from my body across the phone lines to his telling of his embodied experience. Considering his dance floor perspective helps me to factor body language and facial expressions into the social geography of memory at the Hollywood Canteen as a together-but-unequal democratic space - an acutely accurate portrait of U.S. notions of integration as "democracy," writ in Mel's memory of moving through racially differentiated Canteen space. The transmission of body language and facial expression is, admittedly, limited in a phone interview. To speak of visual transmission over the voice-concentrated medium of the phone added another layer of embodied awareness - not more or less intimate - but a reconfiguration of the contact points of intimacy to our conversation.

The next time that Mel and I spoke, he set his Hollywood Canteen memories within a longer trajectory organized around his life as an actor and singer. He told of leaving Denison, Texas, after his high school graduation in 1942, struggling to find housing ("skid row") and work (a busboy in a cafeteria) in Los Angeles, and being "discovered" by major figures of black Hollywood, actor Mantan Moreland and actor/agent Ben Carter, who helped him land the title role in the MGM patriotic short film Shoe Shine Boy (1944). At the same time that the pathway he had hoped and struggled for was rolling out to meet him, the impending interruption of military service loomed. He enlisted in the Marines, hoping to be trained in Southern California, but was sent to a segregated black training camp in North Carolina. When Mel returned to Los Angeles on leave in 1944, he arrived as a Marine on a furlough, but also, importantly, as an actor 
who had made one movie and hoped to renew contact and resume his Hollywood career.

Mel's stories of Montford Point, like his stories of Hollywood, tell of navigating courses paved in paradox, maddening combinations of possibility and restriction. He weaves in and out of Montford Point and the Hollywood Canteen as he tells me about that time; and indeed, there are more intersections than one might imagine. A movie star acquaintance from Hollywood - Tyrone Power was serving as a Marine in North Carolina at the same time as Mel. In one story, Mel tells how his friend, the famous actor, took him to see the swimming pools at nearby Cherry Point where the white Marines were based. This is a story of his friendship with a big star, but it is also a story of segregated and unequal conditions for black Marines. Montford Point also had a pool, he tells me, but black Marines couldn't use it, only the white officers. ${ }^{28}$

The proximity and restrictions from swimming pools and movie stars at Montford Point mirror his stories of placing himself again and again in restricted Hollywood, where he is successful, wellliked, but always out-of-bounds. On leave in Los Angeles, he stayed as a guest in the home of the black actor and agent who had discovered him, Ben Carter. Wearing his Marine uniform, he boarded the Red Car and rode west and north to the Hollywood Canteen. His voice is slow and low when recounting his approach.

The Canteen was a very strange place. You know, you'd go up to the front door, like usually you'd go with two or three other buddies in the service. And they would sit you down on one side of the building, and the whites on the other side of the building. And the first time they did that, I was wondering what was going on. Are they leading us to slaughter? I thought they were going to drop us off in a pit or something. We Sherrie couldn't dance with any of the stars. ${ }^{29}$

Slaughter. Pit. Word choices, rather than the even keel of his measured speech and baritone voice, conveyed the anger and hurt he ascribed to unequal togetherness.

I asked if there were black hostesses on the nights he was there, to which he replied, "No, no. Oh, no."

"So you're describing a kind of segregation?" I asked, still on a mission, it seems, to classify the place as inclusive or exclusive.

"That's what it was," said Mel, "segregation. Bette Davis, she tried her best to break it down. She was all against it. But the powers-that-be won out." Again he advised me to take stories about integration in Hollywood with a grain of salt.

I've heard some of those tales about how we were welcome anywhere. The Ambassador Hotel is there in Hollywood. I went to see Lena Horne there. The man took me and sat me right in the kitchen almost. I couldn't see Lena for the kitchen. ${ }^{30}$

I returned to the question of rules and policy, only this time I was more careful to work it as one dimension of the unpredictable, improvised volunteer setting of unequal togetherness he had described in our first conversation. Did rules factor into body language, facial expressions, and being led to a far corner of the room?

"There had to be a rule, Sherrie, for it to be that blatant. It was so obvious that we were separate. Like later on they said, 'separate but equal,' but we weren't equal." He was, of course, paraphrasing the now historic 1954 Brown v. Board of Education decision that overturned legalized segregation in the United States, a reminder that legal precedent would not incorporate this logic until a decade after his Canteen visits and military service.

"If it was really equal, it wouldn't need to be separate," I echoed. 
Swing: From Time to Torque
"No," said Mel, "We'd be all together." As we wrapped up our conversation, Mel talked about his later movies and television shows, his relentless efforts to integrate professional and public spaces in Las Vegas and Hollywood throughout his career, and the lingering exclusions. Painful among his postwar examples was his story of being denied entry when he tried to see his former Marine Captain, Bobby Troupe, perform at a Hollywood nightclub.

Just before we hung up, I pulled us once more toward the Hollywood Canteen. I asked Mel if he remembered any black volunteers at the club, celebrities perhaps.

He paused for a minute. "I remember Louise Beavers said she was going out one night, but I don't know if they let her in or not." He chuckled. "I'm sure they must have. Surely they wouldn't turn her out. Because she had just done that picture, Imitation of Life with Claudette Colbert, where she played the black lady that made a fortune for the white woman." $\mathrm{He}$ laughed. "Yeah, I'm sure they let her in!"31

The rhetorical mode again: a critical, not literal spin, as I took it, but one that torqued the either/or of the together-butnot-equal basis of inclusion that Mel connected with the Hollywood Canteen within his broader repertoire of World War II memories. Black people were allowed in these together-but-not-equal spaces (the Canteen, Hollywood, the military), but only within the same social relations as depicted in the movies: never equals, always at the service of white people. The uncomfortable tangle of a soldieractor relegated by race to the far corners of the room excludes him, even while it includes him in a space that was advertised at the time, and celebrated for decades afterward, as the apex of progressive movie star-soldier hospitality. His presence may have supplied evidence for some dancers that the Canteen was sim- ply and easily integrated. But Mel, throughout our interview, has pushed back at this interpretation, applied torque by exposing the torqueless results of a democratic dance of the colorblind leading the colorblind. He reads others reading his body, and he narrates the contradictions of Canteen inequality: it is wonderful on the one hand, and hierarchical and racially exclusive on the other. The Canteen is rendered a barely open door - like that of the MGM commissary, the lounge in the Ambassador hotel, casting calls in the motion picture industry - one that had to be used again and again, under uncomfortable and sometimes humiliating circumstances, if it was ever going to provide entry. To perform, in our interview, the stickiness of this door seemed a way for Mel to write/right himself as an actor on the democratic dance floor. This together-but-not-equal integration, as remembered and narrated by Mel, included being allowed in (unlike most Hollywood nightclubs), then being led to certain parts of the club with other black servicemen, not being allowed to dance with the stars, feeling more tolerated than welcomed, and not seeing any black hostesses.

Mel's narrative of not dancing torques the inclusion model of integration, turning Hollywood (and U.S.) democracy to face the contradictions of unequal togetherness. Some stories about achieving torque on the dance floor also "torque back": when people narrate dance floor memories in such a way as to channel expectations of the typical telling of democratic dancing, and then lean at a bit of a different angle, bend the knees a little more, shift the play of pattern and surprise, turning it into something else. These are the moments when narrative pressure applied to the dance floor of the nation produces a different kind of dance floor democracy. 
J eni LeGon (born Jennie May Ligon) was a well-established dancer in theaters and movies, a chorus line organizer, and a dance teacher when she began receiving calls to bring her chorus line and dance students up from the Eastside to the Hollywood Canteen two or three times a month between November 1942 and April 1943. She was still a well-known dancer and dance teacher when I first interviewed her in 2004. In her late eighties, she was enjoying her celebrity amid the tap revival. She maintained an active schedule, giving workshops around the world, and speaking about her long career that spanned from the chorus line of the Count Basie Orchestra in the early thirties, to seasons on black vaudeville with the Whitman Sisters, to an on-andoff relationship with the motion picture industry, dictated by the limits of success in Hollywood for black artists. Her dance sequences were often truncated or cut, a pattern she attributes to the jealousy of powerful white women stars who did not wish to be upstaged.

In 1941, she helped her brother, Alfred Ligon, purchase books in preparation of opening the first black bookstore in Los Angeles, and she ran her dance school out of the same building on East Jefferson in the Central Avenue District. It was in the midst of her varied career training dancers, putting acts together, and performing in clubs, theaters, and movies that someone called her up and asked her to bring her chorus line to volunteer at the Hollywood Canteen. "They just called me directly and asked me if I could bring the girls down. At first I objected." As she recalled, the caller explained that the Canteen "needed black girls to dance with the black boys. And I said, 'Well, I don't like that.' And they said, 'Well, that's the rules,' or something like that." She thought it over and decided to take her dancers up to Hollywood. "I figured, well, the boys were putting their lives on it, so it didn't Sherrie hurt us to do that, you know. I didn't like Tucker it particularly."32

Jeni narrated her integration of the hostess-side of the Canteen as a moral compromise. She agreed to dance, not in order to approve of the Canteen as a symbol of democracy, but to support black soldiers who would otherwise be ignored in a club that white liberals viewed as integrated. Importation of black hostesses for clubs in locations where black people did not-and were not allowed to - live was a common solution for some white-dominated Usos and Uso-like Canteens that "welcomed" soldiers of color, while at the same time preventing mixed dancing. Although the black press vociferously critiqued the many Jim Crow canteens that turned black soldiers away, the same newspapers did not fault those that called upon black hostesses to integrate the dance floors of clubs in whiterestricted areas such as Hollywood. Instead, the readiness of black communities to supply last-minute hostesses was celebrated as an expression of the Double Victory campaign, combating racism at home and fascism abroad. For example, in a March 1943 story in the California Eagle, the secretary of the segregated black musicians union local 767, Florence Cadrez, was congratulated for securing "Mates for Sailors" when a Canteen Officer of the Day called her up with the emergency alert that "9o Negro sailors were arriving at the Hollywood Canteen in two hours." Cadrez was able to rustle up "3o Negro girls” who "were ready and waiting when the sailors arrived."33

But in recounting the integrated Hollywood Canteen's dependence on the lengthy commutes of black women from the Eastside on an on-call basis, Jeni's narrative takes us to the other side of that phone call, to the point of view of a black dancer and actress. To secure black "mates" for 
Swing: black men is cause for hesitation because From Time of the racist history that constructs black to Torque men as predators of white women. The labor of all hostesses was to cheerfully entertain all military guests, but while some white interviewees told stories of dancing across race without incident, others spoke of being instructed not to dance across race, and even of a shore patrol officer who beat up black men who danced with white hostesses. By this logic, the labor of imported black hostesses ensured same-race democratic dancing, enlisting black hostesses in the service of whiteness that can see itself as inclusive. But, as Jeni told me in our interview, the city had far more welcoming places for black soldiers - not in Hollywood, but in the Eastside. "They could come to the black clubs, in the black neighborhood, which was Central Avenue, of course. We had a whole bunch of clubs and they could come there and have a ball if they wanted to, you know. But the Hollywood Canteen was supposed to be top dog... so, naturally everybody wanted to go ... because it was Class A."

But one night...there was one white boy on the floor dancing with different girls and they weren't dancing very well, and I was dancing with one of the black boys, and [the white boy] was watching me and I was watching him because he was such a damn good dancer. So, anyway, what turned out was that he came and asked me to dance with him and I said sure. And we went out and started jittering, and everybody on the floor moved out and let us take the floor and we just had a ball. And he and I danced all over that bloody room that time. And everybody just stood back and cheered and carried on, and it was really fun. I mean, you know, just the black and white thing and that was the end of it, but this particular night, we showed them it just didn't have to be that way. We were just rhythmically wedded, you know what I mean, we just danced similarly and we were good together. And so that's what it was. He'd throw me out and I'd come back, we'd do the boogie, all that sort of business. It was just a fun thing, and we were having such a good time, he and I, you know, enjoying one another's ability to do the things that we could do together, not having seen one another or known anything about one another before.

I heard Jeni's telling of this story as an artistic othering in which she animates her younger self at the Hollywood Canteen as a political actor who torques her intended role as an othered political action figure. She narrates herself and her dance partner as modeling alternative notions of democracy on the dance floor, while other national subjects watch and cheer. In saying yes to the white soldier, not because she "can't say no" but because she thinks he is a damn good dancer, she is saying no to a nation that imagines black male predators and white female prizes. And in narrating this dance as taking place in a segregated environment, she says no to Hollywood's claims to colorblindness. While critical of the official story, Jeni's story also highlights a utopian vision of interracial jitterbugging at the Hollywood Canteen, albeit from the point of view of a black woman exercising agency. Dance floor democracy, in her telling, is not guaranteed. It is achieved in the moment, among a small set of dancers attuned to each other's moves and a crowd of appreciative onlookers, within and against and despite constraints. And it is achieved in the interview, as she torques back in what she chooses to tell the academic, whose questions, inflections, and responses also exert energy in this transaction.

$\mathrm{Me}$ Bryant and Jeni LeGon are just two of sixty former Canteen-goers who shared with me their very different narra- 
tives of navigating the swing dance floor of the nation sixty-five years after the fact. As I listened to former Canteen-goers traverse the social geographies of memory, narrating in the present their youthful swing dancing bodies moving through patriotically charged space, I could usually pick up some strains of the unified feelgood version of World War II swing nostalgia (pitched at different volumes); but I also heard it actively pushed and pulled by narrators approaching it through unique orientations to its social geography. Even those whose memories most resembled the sentiments expressed by nostalgia offered insights into the difference it makes to imagine an embodied point of view from one or the other side of the jitterbugging couple.

In our interviews, former Canteen-goers danced with and against the footsteps of that idealized jitterbugging couple. A
Hollywood Canteen analysis that could Sherrie include them all would torque the official Tucker story through differentiated dance floor travels, yielding both less and more room to move. In telling the dance floor of the nation as a place where some bodies achieve flight, some bodies are grounded, and some bodies are injured, we accommodate more restrictions, but also more interpretative space, more unexpected turns, more critique. In fact, one could say that in their differences, dissonances, and sporadically achieved torque, the Canteen interviewees achieve more democracy if the goal of a democratic dance floor is not only to divide people in half and match (some of) them in ideologically appropriate paired units of lead/follow, but also to create a space where all orientations pull, all touches transmit and receive signals, and all bodies and power relations are weighted into the equation.

\section{ENDNOTES}

Author's Note: This article is drawn from my forthcoming book, Dance Floor Democracy: The Social Geography of Memory at the Hollywood Canteen (Duke University Press). I am very grateful to Ken Wissoker and the anonymous readers for all their feedback about this project. I am also grateful to all the interviewees, as well as the copanelists and participants at conferences, talks, and seminars, all of whom have turned me in ways that helped me get this work off the ground at key moments. A special thank you to Christopher Wells for the dance lessons, both theory and practice. Thank you also to Duke University Press for permission to publish this section in article form.

${ }^{1}$ Sara Ahmed, On Being Included: Racism and Diversity in Institutional Life (Durham, N.C. : Duke University Press, 2012), 49.

2 See, for example, "No Jim Crow at Calif. Canteen," Afro-American, May 8, 1943; "Bette Davis Upholds Mixed Couples at Movie Canteen," Chicago Defender (national edition), January 9, 1943 ; and "Canteen Heads Have Row over Mixed Dancing," Down Beat, April 15, 1943, 1.

3 James Spada, More Than a Woman: An Intimate Biography of Bette Davis (New York: Bantam Books, 1993), 193; Bette Davis with Michael Herskowitz, This 'N That (New York: G.P. Putnam's Sons, 1987), 128; and David W. Stowe, Swing Changes : Big-Band Jazz in New Deal America (Cambridge, Mass. : Harvard University Press, 1994), 161-162.

4 Marianna Torgovnick, The War Complex: World War II in Our Time (Chicago: University of Chicago Press, 2005), 2.

5 LeRoi Jones/Amiri Baraka, "Swing: From Verb to Noun” (1963), reprinted in The LeRoi Jones/Amiri Baraka Reader, ed. William J. Harris (New York: Thunder's Mouth Press, 1991), $33-50$. 
Swing: 6 Nathaniel Mackey, “Other: From Noun to Verb,” in Jazz Among the Discourses, ed. Krin GabFrom Time $\quad$ bard (Durham, N.C.: Duke University Press, 1995), 76 - 99.

to Torque 7 Ahmed, On Being Included, 43.

8 Mackey, “Other: From Noun to Verb," 76- 77.

9 Danielle Goldman, I Want to Be Ready: Improvised Dance as a Practice of Freedom (Ann Arbor: University of Michigan Press, 2010), 22.

10 Ibid., 54 .

11 Perry A. Hall, “African-American Music: Dynamics of Appropriation and Innovation,” in Borrowed Power: Essays on Cultural Appropriation, ed. Bruce H. Ziff and Pratima V. Rao (New Brunswick, N.J. : Rutgers University Press, 1997), 31- 51.

12 Inderpal Grewal, Transnational America: Feminisms, Diasporas, Neoliberalisms (Durham, N.C.: Duke University Press, 2005), 19.

13 Nikhil Pal Singh, Black Is a Country: Race and the Unfinished Struggle for Democracy (Cambridge, Mass. : Harvard University Press, 2004), 17.

14 Kevin Whitehead, Why Jazz? : A Concise Guide (New York: Oxford University Press, 2011), 10.

15 Joel Dinerstein, Swinging the Machine: Modernity, Technology, and African American Culture between the World Wars (Amherst: University of Massachusetts Press, 2003), 258.

16 Lewis A. Erenberg, Swingin' the Dream: Big Band Jazz and the Rebirth of American Culture (Chicago: University of Chicago Press, 1998), 52.

17 Howard Spring, "Swing and the Lindy Hop: Dance, Venue, Media, and Tradition," American Music 15 (2) (1997): 191; and Marshall and Jean Stearns, Jazz Dance: The Story of American Vernacular Dance (New York and London: Schirmer Books, 1979), 315-316.

18 Terry Monaghan, “Stompin' at the Savoy - Remembering, Re-Enacting and Researching the Lindy Hop's Relationship to Harlem's Savoy Ballroom,” in Dancing at the Crossroads : African Diasporic Dances in Britain: Conference Proceedings, ed. Caroline Muraldo, Mo Dodson, and Terry Monaghan (London: London Metropolitan University, 2005), 36.

19 Robert P. Crease, “Divine Frivolity: Hollywood Representations of the Lindy Hop, $1937-$ 1942," in Representing Jazz, ed. Krin Gabbard (Durham, N.C. : Duke University Press, 1995), $209-210$.

20 Ethnomusicologist Christopher Wells experiences this difference between what looks linear from the outside and what he experiences as a dancer as a "tension and release feel," in which even the slotted send-out associated with West Coast style is hardly linear, but built from the gathering and sending of energy. Christopher Wells, conversation/demonstration, Charlotte, North Carolina, April 2012.

${ }^{21}$ Kenneth Laws and Arleen Sugano, Physics and the Art of Dance: Understanding Movement, 2nd ed. (Oxford and New York: Oxford University Press, 2008), $70-71$.

22 Brenda Dixon Gottschild, Digging the Africanist Presence in American Performance (Westport, Conn., and London: Praeger, 1996), 56, 22.

23 Dinerstein, Swinging the Machine, $258-268$.

24 Alessandro Portelli, The Death of Luigi Trastulli, and Other Stories: Form and Meaning in Oral History (Albany: State University of New York Press, 1991), viii - ix.

25 Hancock was speaking of predominantly white revivalists in the 1990s. See Black Hawk Hancock, "American Allegory: Lindy Hop and the Racial Imagination," Ph.D. dissertation, University of Wisconsin-Madison (2004). See also Eric Usner, "Dancing in the Past, Living in the Present: Nostalgia and Race in Southern Californian Neo-Swing Dance Culture," Dance Research Journal, Congress on Research in Dance 33 (2) (2001): 87-111; and Juliet McMains and Danielle Robinson, "Swinging Out: Southern California’s Lindy Revival," in I See America 
Dancing: Selected Readings, 1685 -200o, ed. Maureen Needham (Urbana: University of Illinois Sherrie Press, 2002), 84-91.

${ }^{26}$ Mel Bryant, telephone interview with author, July 25, 2000.

27 Ibid.

28 Mel Bryant, telephone interview with author, October 28, 2000.

29 Ibid.

30 Ibid.

31 Ibid.

32 Jeni LeGon, telephone interview with author, November 26, 2004.

33 “Flo Cadrez Gets Mates for Sailors,” California Eagle, March 17, 1943. 